\title{
Upaya pengembangan kuliner tradisional puluik pucung di Kecamatan Kuantan Mudik Kabupaten Kuantan Singingi
}

\author{
Basri*, Yoserizal, dan Yesi \\ Universitas Riau \\ * basri@ lecturer.unri.ac.id
}

\begin{abstract}
Abstrak. Kuliner tradisional penuh dengan citarasa dan khas di daerah seperti puluik pucung di Kuantan Mudik. Puluik pucung selama ini hanya dibuat untuk mengisi perhelatan saja, padahal potensi untuk dipasarkan cukup tinggi. Kegiatan pengabdian masyarakat akan dilaksanakan di Kecamatan Kuantan Mudik Kabupaten Kuantan Singingi. Sasaran kegiatan pengabdian ini adalah yakni aparat desa, masyarakat Desa Kuantan Mudik yang memiliki kemampuan untuk mengolah dan membuat puluik pucung tersebut. Adapun tujuan kegiatan pengabdian merumuskan bersama masyarakat tentang variasi rasa serta cara-cara pengembangan dan pemasaran dari puluik pucung, dan menemukan media-media yang cocok sebagai sarana pengembangan dan pemasaran. Hasil pengabdian kepada masyarakat dapat dilihat dari kemampuan pemahaman peserta akan materi yang disampaikan sangat baik terlihat dari pertanyaan-pertanyaan yang disampaikan pada sesi diskusi. Peserta mampu menyerap dan menanggapi materi yang disampaikan oleh tim penyuluhan terkait dengan potensi pengembangan dan pemasaran puluik pucung. Kegiatan ini juga memberikan pengetahuan kepada peserta mengenai cara yang tepat dan benar dalam mengembangkan potensi kue-kue tradisional lainnya agar lebih dikenal dan diminati oleh masyarakat luas.
\end{abstract}

Kata kunci: kuliner tradisional; puluik pucung; Kuantan Singingi

\begin{abstract}
The traditional cuisine is usually full of flavors and is typical of certain regions. An example is a Puluik pucung in Kuantan Mudik. Puluik Pucung has only been made to fill the event, even though the potential to be marketed commercially is quite high. This empowerment activity is carried out in Kuantan Mudik Subdistrict, Kuantan Singingi Regency. The target of this activity is the village apparatus, the people of Kuantan Mudik Village who have the ability to make the Puluik Pucung. The purpose of the community empowerment activities are to form the variety of flavors and ways of developing and marketing the puluik pucung, and finding suitable media as a means of developing and marketing. The results of community service can be seen from the ability of the participants' understanding of the material presented was very good as seen from the questions presented at the discussion session. Participants are able to absorb and respond to the material presented by the extension team related to the potential for development and marketing of puluik pucung. This activity also provides knowledge to participants about the right and correct ways to develop the potential of other traditional cuisines to be known and likely by outside communities.
\end{abstract}

Keywords: traditional cuisine; puluik pucung; Kuantan Singingi

To cite this article: Basri, Yoserizal, \& Yesi. 2019. Upaya pengembangan kuliner tradisional puluik pucung di Kecamatan Kuantan Mudik Kabupaten Kuantan Singingi. Unri Conference Series: Community Engagement 1: 286289 https://doi.org/10.31258/unricsce.1.286-289

(C) 2019 Authors

Peer-review under responsibility of the organizing committee of Seminar Nasional Pemberdayaan Masyarakat 2019 


\section{PENDAHULUAN}

Objek wisata tidak hanya selalu identik dengan alam seperti gunung, sungai, laut, pantai, atau berupa objek bangunan seperti museum, benteng atau objek peninggalan sejarah lainnya. Berbagai kekayaan kuliner yang menjadi tradisi masyarakat lokal juga dapat dikembangkan sebagai daya tarik wisata guna membantu perekonomian masyarakat.

Keberfungsian wisata saat ini selain dari menciptakan suasana yang menarik juga mampu meningkatkan perekonomian masyarakat setempat yang berada di daerah kawasan objek wiata tersebut. Hal ini di karenakan wisata yang tercipta itu ada yang terbentuk secara alamiah dan juga ada yang terbentuk secara non alamiah. Berwisata pada dasarnya merupakan langkah utama yang dilakukan oleh seseorang untuk menghila ngkan rasa kejenuhannya setelah melakukan berbagai aktifitas sehari-hari yang begitu padat, sesungguhnya berwisata adalah hal terpenting yang harus di lakukan oleh sesorang untuk menghilangkan rasa kesumpekan atau stress dalam menjalani kehidupan ini, manusia sesungguhnya memiliki sifat (Homoluden) yaitu selalu butuh yang namanya rekreasi atau hiburan.

Indonesia kaya akan beraneka ragam kuliner khas yang dapat menarik minat dan selera masyarakat karena kaunikan dan kelezatan nya. Kuliner tradisional ini biasa nya penuh dengan citarasa dan khas pada daerahdaerah tertentu. Contohnya adalah puluik pucung di Kuantan Mudik. Puluik pucung selama ini hanya dibuat untuk mengisi perhelatan saja, padahal potensi untuk dipasarkan secara komersial dan berkala cukup tinggi. Dimana masyarakat akan selalu mentikan kehadiran kuliner ini disetiap acara-acara adat di Desa.

Puluik pucuang memiliki rasa yang enak dan gurih terbuat dari ketan dan sntan membuat rasanya khas dan berkesan bagi orang-orang yang memakannya. Berbeda dengan lapek bugih atau jenis jajanan traditional lainnya yang dapat dengan mudah kita temui secara rutin di pasar-pasar ataupun gerai yang ada

\section{METODE PENERAPAN}

Metode pengembangan dan penerapan yang akan dilaksanakan merupakan sebuah rangkaian tahapan yang disusun secara sistematis, yaitu 1).Persiapan, 2.)Pelaksanaan: Sosialisasi kepada masyarakat Desa Kuantan Mudik Kabupaten Kuantan Singingi mengenai pentingnya mengidentifikasi potensi kuliner puluik pucuang yang dapat dikembangkan menjadi wisata kuliner. Rekomendasi dalam bentuk model atau media pemasaran untuk pengembangan puluik pucuang di Kuantan Mudik. 3).Evaluasi dan 4).Pelaporan.

\section{HASIL DAN KETERCAPAIAN SASARAN}

Kecamatan Kuantan Mudik merupakan salah satu kecamatan yang berada di Kabupaten Kuantan Singingi yang mempunyai jumlah penduduk 23.916 jiwa dengan luas wilayah 732,95 Km2 dan terdiri dari 24 desa/kelurahan. Kecamatan Kuantan Mudik yang beribukota di Lubuk Jambi mempunyai 23 desa dan 1 kelurahan yang definitif, sampai akhir tahun 2017, terdapat 65 dusun di Kecamatan Kuantan Mudik. Dengan rata - rata 3 dusun tiap desa.

Jumlah Penduduk Kecamatan Kuantan Mudik pada Tahun 2017 berjumlah 24.163 jiwa, yang terdiri dari 12.180 jiwa laki-laki dan 11.983 jiwa perempuan. Dengan Sex Rasio sebesar 102, menunjukkan tidak adanya perbedaan yang sangat besar untuk komposisi jumlah penduduk laki-laki dan perempuan, karena dalam 100 orang perempuan terdapat 102 orang laki - laki. Dengan luas wilayah Kecamatan Kuantan Mudik 732,95 KM2 dan jumlah penduduknya 24.163 jiwa, menghasilkan kepadatan penduduk sebesar 33 yang artinya dalam setiap 1 KM2 dihuni oleh sekitar 33 penduduk. Kecamatan Kuantan Mudik mempunyai 5.814 rumah tangga dengan rata-rata jumlah penduduk dalam rumah tangga adalah 4 orang. Jumlah tersebut hampir merata di semua desa/kelurahan.

Kegiatan ini memberikan pemahaman kepada peserta, Cara-cara pengembangan citarasa dan variasi dari puluik pucung. Selanjutnya memberikan wawasan terkait media-media yang cocok sebagai sarana pengembangan dan promosi puluik pacung serta bagaimana keterkaitan antara potensi Pasar, Pemasaran dan kemasan yang menarik dalam meningkatkan hasil promosi. Kegiatan ini juga memberikan pengetahuan kepada peserta mengenai cara yang tepat dan benar dalam mengembangkan potensi usaha secara online atau melalui sosial media. 

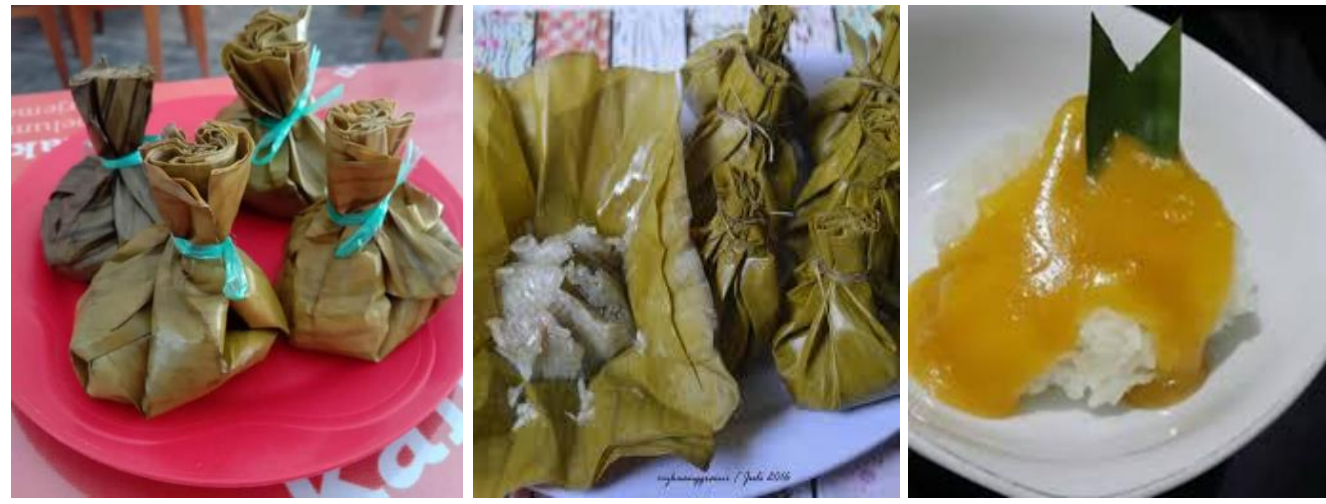

Gambar 1. Makanan Tradisional Puluik Pucung (original)

Potensi makanan tradisional bernilai ekonomis dengan upaya pengembangan makanan tradisional puluik pucung melalui peningkatan ragam variasi rasa atau isi dan Topping, seperti dibawah ini:
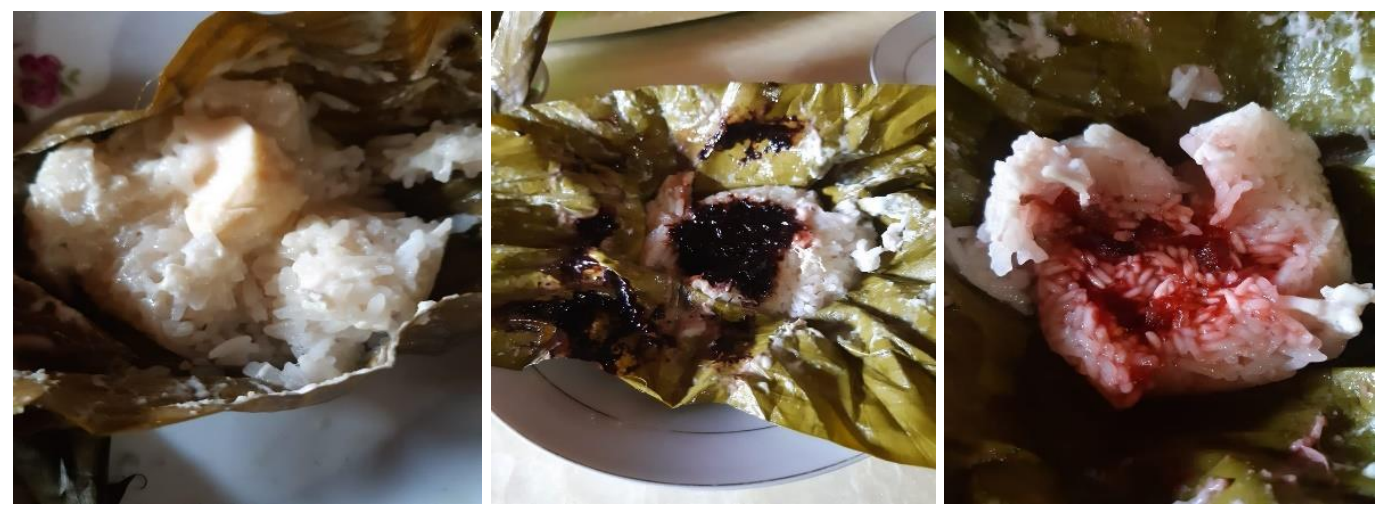

Gambar 2. Variasi isi Puluik Pucung : Keju, Coklat dan Strawberry
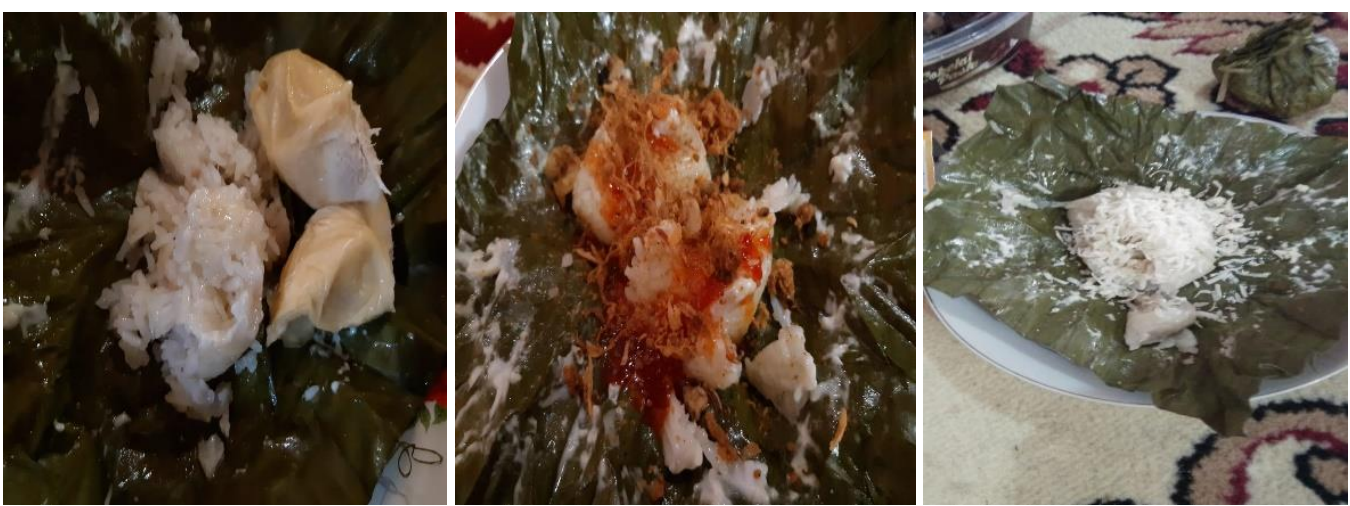

Gambar 3. Variasi Topping Puluik Pucung : Durian, Abon cabe, dan Keju

Selain itu, pengembangan pengetahuan agar menjadi Pengusaha makanan yang berhasil yaitu yang selalu kreatif dalam membuat makanan ringan yang berbeda, sehingga membuat produk tersebut lebih gampang ditemukan dan dapat dibedakan oleh konsumen dari segi kemasan misalnya. 

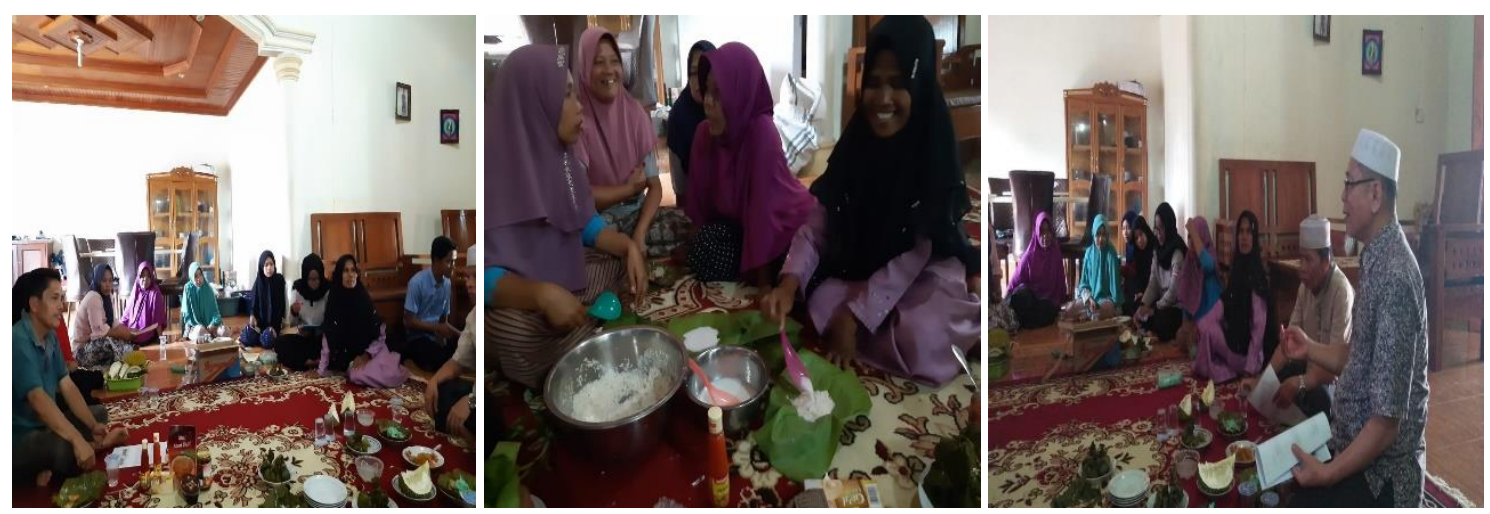

Gambar 4. Antusias peserta mendengar pengarahan dari tim pengabdian masyarakat

Maka dari itu tidak masalah apabila produk yang di jual telah banyak disetiap tempat, asalkan makanan yang dijual tersebut berbeda dengan produk yang sudah beredar, misalnya dengan membuat variasi rasa, bentuk dan kemasan yang menarik.

\section{KESIMPULAN}

Dari hasil pengabdian dapat disimpulan bahwa kegiatan ini berhasil berjalan dengan baik. Kemampuan tim pengabdian dalam menyajikan materi dan memberikan materi terkait dengan upaya pengembangan makanan tradisional puluik pucung melalui peningkatan ragam variasi puluik pucung dan media pemasaran sudah sangat baik, hal ini dapat dilihat dari ketertarikan dan antusias ibu-ibu PKK dalam mengikuti pelaksaan kegiatan pengabdian.

Materi penyuluhan dan diskusi sangat menarik dimana makanan yang akan 'berpotensi' di jual di Pasaran harus memiliki kualitas yang baik, baik dari segi bahan dasar yang dipakai, segi pembuatan maupun dari segi packaging. Bahan dasar yang digunakan bersih dan tidak mengandung unsur zat yang berbahaya. Cara pembuatannya pun harus sesuai prosedur. Kemudian wadah makanan ringan yang telah selesai di masak sebaiknya menggunakan kemasan yang baik dan menarik.

\section{DAFTAR PUSTAKA}

Altman, I. 1980. Culture and Environment. California: Brooks/Cole Publishing

Brannen, J. 2002. Memadu Metode Pengabdian Kualitatif \& Kuantitatif. Jakarta: Pustaka Pelajar.

Suparlan, P. 1984. Manusia Kebudayaan dan Lingkungannya. Jakarta: PT. Raja Grafindo Persada Jakarta.

Danumihardja, S. 1987. Model Pengembangan Desa: Sebuah Kajian Sosiologi Arsitektur Perdesaan di Jawa Barat. Tesis Magister Arsitektur, Program Pasca Sarjana-ITB.

Doxiadis, C. A. 1968. Ekistics: An Introduction to The Science of Human Settlement. New York: Oxford University Press.

Garna, Y. 1984. Pola Kampung dan Desa, Bentuk serta Organisasi Rumah Masyarakat Sunda. Bandung: Pusat Ilmiah dan Pengembangan Regional (PIPR).

Nuryanto. 2007. Kajian Pola Kampung dan Rumah Tinggal pada Arsitektur Tradisional Kasepuhan Ciptagelar dan Kasepuhan Ciptarasa, Kab. Sukabumi, Jawa Barat. Laporan Penelitian, Jurusan Pendidikan Teknik Arsitektur, FPTK Universitas Pendidikan Indonesia.

Pribadi, J. 1978. Perencanaan Desa. Direktorat Penyelidikan Masalah.

Rapoport, A. 1977. Human Aspecs of Urban Form: Towards a Man Environment Approach to Urban Form and Design. New York: Oxford University Press.

Soedjito. 1987. Aspek Sosial Budaya dalam pembangunan pedesaan. Yogyakarta: PT Tiara Wacana Yogyakarta. 